\title{
Behaviour of ring bivalents in holokinetic systems: Alternative sites of spindle attachment in Pachylis argentinus and Nezara viridula (Heteroptera)
}

\author{
A. G. Papeschi ${ }^{1}$, L. M. Mola ${ }^{1}$, M. J. Bressa ${ }^{2}$, E. J. Greizerstein ${ }^{1}$, V. Lía ${ }^{1}$ \& L. Poggio ${ }^{1}$ \\ ${ }^{1}$ Lab. de Citogenética y Evolución, Depto. de Ecología, Genética y Evolución, Fac. Cs. Exactas y Naturales, \\ Univ. de Buenos Aires. Int. Güiraldes y C. Norte, C1428EHA, Ciudad Universitaria, Ciudad Autónoma de \\ Buenos Aires, Argentina; Tel: +54 114576 3349; Fax: +54114576 3384; E-mail:alpape@bg.fcen.uba.ar; \\ ${ }^{2}$ Cátedra de Citología, Facultad de Ciencias Naturales y Museo, UNLP (1900), La Plata, Argentina
}

Received 9 June 2003. Received in revised form and accepted for publication by Herbert Macgregor 29 July 2003

Key words: Heteroptera, holokinetic chromosomes, fluorescent in-situ hybridization, meiosis, ring bivalents, spindle attachment sites

\begin{abstract}
Heteropteran chromosomes are holokinetic; during mitosis, sister chromatids segregate parallel to each other but, during meiosis, kinetic activity is restricted to one pair of telomeric regions. This meiotic behaviour has been corroborated for all rod bivalents. For ring bivalents, we have previously proposed that one of the two chiasmata releases first, and a telokinetic activity is also achieved.

In the present work we analyse the meiotic behaviour of ring bivalents in Pachylis argentinus (Coreidae) and Nezara viridula (Pentatomidae) and we describe for the first time the chromosome complement and male meiosis of the former $(2 n=12+2 m+\mathrm{X} 0$, pre-reduction of the $\mathrm{X})$. Both species possess a large chromosome pair with a secondary constriction which is a nucleolus organizer region as revealed by in-situ hybridization. Here we propose a new mode of segregation for ring bivalents: when the chromosome pair bears a secondary constriction, it is not essential that one of the chiasmata releases first since these regions or repetitive DNA sequences adjacent to them become functional as alternative sites for microtubule attachment and they undertake chromosome segregation to the poles during anaphase I.
\end{abstract}

\section{Introduction}

All heteropteran species possess holokinetic chromosomes (without a localized centromere); during mitosis microtubules attach to the entire length of the sister chromatids and at anaphase they migrate parallel to each other and perpendicular to the polar spindle. At the ultrastructural level, kinetochore plates have been observed covering almost all the surface of mitotic chromosomes (Buck 1968, Comings \& Okada 1972).
However, kinetic activity during meiosis is restricted to the telomeric regions (chromosomes are telokinetic (Motzko \& Ruthmann 1984)). The meiotic behaviour of autosomal bivalents, sex chromosomes, $\mathrm{m}$ chromosomes or autosomal univalents is slightly different (Ueshima 1979, Manna 1984, Papeschi \& Mola 1990, GonzálezGarcía et al. 1996, Suja et al. 2000). As a rule, autosomal bivalents are chiasmatic (except for a few species; see Nokkala \& Grozeva 2000) and rod bivalents orientate axially and segregate pre- 
reductionally. On the other hand, sex chromosomes are achiasmatic and behave as univalents in male meiosis; they divide equationally at anaphase I and associate forming a pseudo-bivalent at meiosis II. Nevertheless, pre-reduction of the sex chromosomes has been described in a few species (Ueshima 1979, Grozeva \& Nokkala 2001). Finally, the $\mathrm{m}$ chromosomes (pair of minute elements present in some families) are also achiasmatic but associate at first meiotic division segregating pre-reductionally.

Although bivalents in Heteroptera are supposed to present as a rule only one chiasma, ring bivalents have been increasingly reported lately (Camacho et al. 1985, Mola \& Papeschi 1993, Bressa et al. 2001a, 2001b, Jacobs \& Liebenberg 2001, Rebagliati et al. 2001, Jacobs \& Groeneveld 2002, Rebagliati et al. 2003). As chromosomes are telokinetic, ring-shaped bivalents should have some difficulties in attaching to the spindle fibres. In two heteropteran species, we described that one of the two chiasmata releases first, leaving one pair of telomeric regions free to attach to the spindle fibres (Mola \& Papeschi 1993).

In the present work the chromosome complement and male meiosis of Pachylis argentinus is described for the first time, and the meiotic behaviour of ring bivalents in P. argentinus (Coreidae) and Nezara viridula (Pentatomidae) is described and analysed. Both species possess a large bivalent with a secondary constriction which frequently shows two chiasmata. The meiotic behaviour of this bivalent suggests that the secondary constrictions (or repetitive sequences closely associated to it) can function as alternative sites for spindle attachment.

\section{Materials and methods}

Adult individuals of Pachylis argentinus (28 males and 10 females from Ciudad Autónoma de Buenos Aires; 7 males and 5 females from La Plata, Buenos Aires Province, Argentina) and Nezara viridula (35 males from Rojas, Buenos Aires Province, Argentina) were studied.

Some males were fixed in the field in $(3: 1)$ ethanol : glacial acetic acid; gonads were dissected out and kept in $70 \%$ ethanol and slides were performed by the squash method in a drop of acetic haematoxylin. Some other individuals were brought alive to the laboratory and, once the gonads were dissected out, they were fixed in $(3: 1)$ ethanol: glacial acetic acid; slides were made in a drop of $45 \%$ acetic acid for in-situ hybridization. Females were kept at $-70^{\circ} \mathrm{C}$ in liquid nitrogen for DNA extraction.

\section{Fluorescent in-situ hybridization}

DNA extraction was performed as described by Marchant (1988) with slight modifications. The 808-bp 18s rDNA probe was obtained by PCR amplification using the primers, Het 62218s F (5'-TTGCGGTTAAAAAGCTCG-3') and Het $143018 \mathrm{~s} \quad \mathrm{R}$ (5'-TCGGAATTAACCAGACAAATC- $3^{\prime}$ ), with $P$. argentinus genomic DNA as template. The probe was labelled by nick translation with biotin 14-dUTP (Bionick Labelling System, GIBCO BRL).

For hybridization experiments, the hybridization mixture was denatured for $15 \mathrm{~min}$ at $70^{\circ} \mathrm{C}$. The slides were placed on a thermocycler for $7 \mathrm{~min}$ at $81^{\circ} \mathrm{C}$ (denaturation), $10 \mathrm{~min}$ at $45^{\circ} \mathrm{C}$ and $10 \mathrm{~min}$ at $38^{\circ} \mathrm{C}$. The slides were then incubated at $37^{\circ} \mathrm{C}$ overnight for hybridization. Slides were washed in high-stringency conditions. To detect biotinlabelled probes, they were treated with conjugate Streptavidine-Cy3 (red). Slides were counterstained with 4'6-diamidino-2-phenylindole (DAPI) $(1 \mu \mathrm{g} / \mathrm{ml}$ in Mcllvaine's, citrate buffer, $\mathrm{pH}=7)$, for $10 \mathrm{~min}$ at room temperature and then mounted in antifade solution. Slides were examined with a Leica epifluorescence microscope with appropriate filtres. Photographs were taken using Kodak colour Supra print film 400 ASA.

\section{Results}

Pachylis argentinus possesses $2 n=15=12+$ $2 m+\mathrm{X} 0$ (male; Figure 1a). Two large, two medium-sized and two small autosomal pairs are distinguished; the $\mathrm{X}$ chromosome is similar in size to the smallest autosome and the $m$ pair is noticeably smaller. One of the two largest autosomal pairs presents a secondary constriction in a medial position (Figure 1e, g).

The $\mathrm{X}$ chromosome is positively heteropycnotic from leptotene to late diakinesis (Figure 1b-g). 


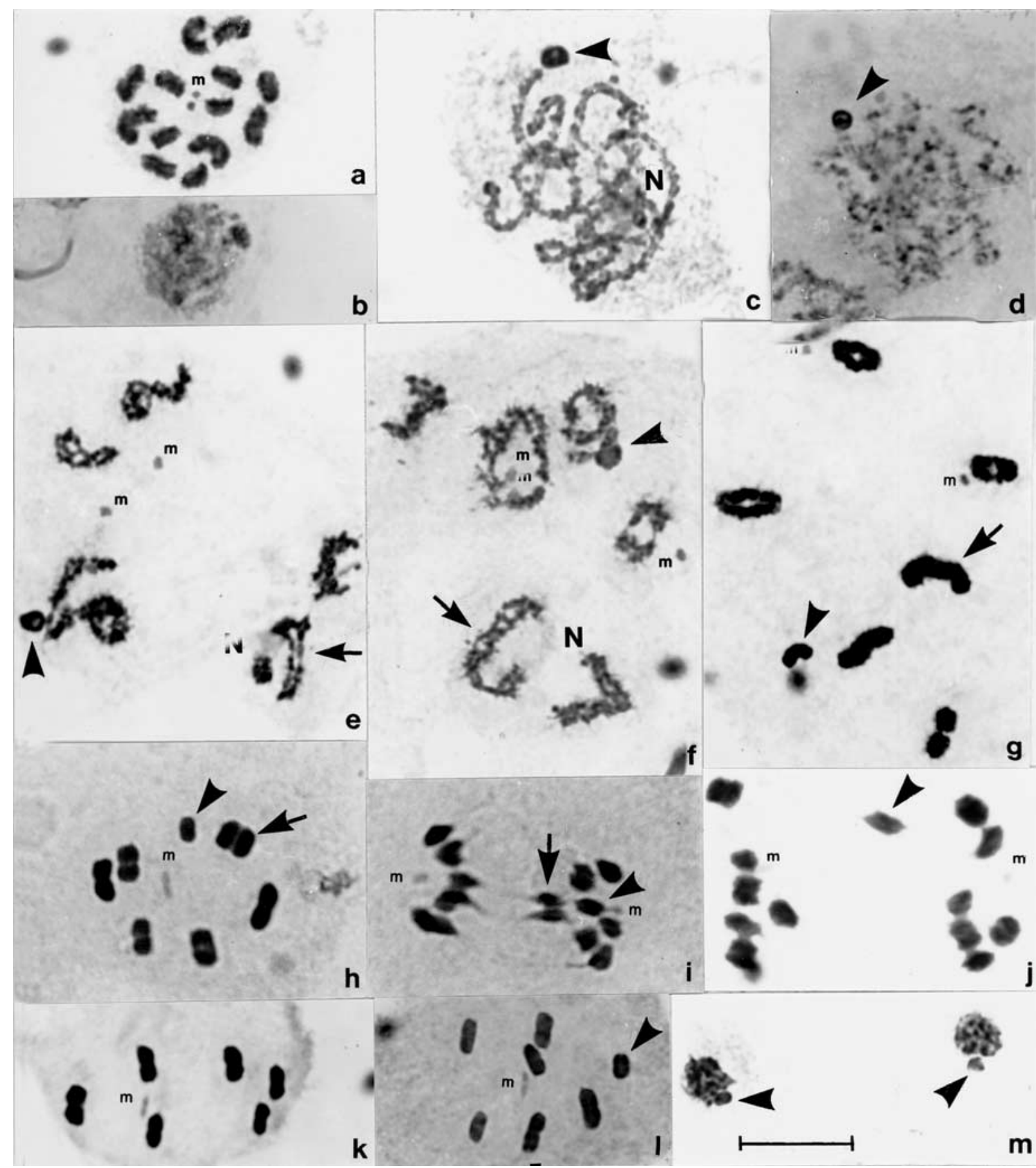

Figure 1. Male meiosis in Pachylis argentinus $(2 n=12 \mathrm{~A}+2 m+\mathrm{X} 0)$. (a) Spermatogonial prometaphase. (b) Leptotene-zygotene. (c) Pachytene. (d) Diffuse stage. (e, f) Diplotene. (g) Diakinesis. (h) Metaphase I. (i) Anaphase I; arrow points to the lagging segregating bivalent. (j) Telophase I. (k, I) Metaphase II without (k) and with (I) X chromosome. (m) Telophase II nuclei with X chromosome. $\mathrm{Bar}=10 \mu \mathrm{m}$. Arrows point to the bivalent with the secondary constriction; arrowheads show the $\mathrm{X}$ chromosome. $\mathrm{N}=$ nucleolus; $\mathrm{m}=$ chromosomes. 
Table 1. Percentage of cells at diakinesis-metaphase I in which the NOR bivalent presents two chiasmata.

\begin{tabular}{|c|c|c|c|c|c|}
\hline \multicolumn{3}{|c|}{ Pachylis argentinus } & \multicolumn{3}{|c|}{ Nezara viridula } \\
\hline Individual & $\%$ & No. of cells & Individual & $\%$ & No. of cells \\
\hline 1 & 38.5 & 43 & 1 & 28.3 & 35 \\
\hline 2 & 28.7 & 126 & 2 & 15.5 & 67 \\
\hline 3 & 5.8 & 54 & 3 & 36.6 & 76 \\
\hline 4 & 12.0 & 64 & 4 & 27.5 & 134 \\
\hline 5 & 23.6 & 88 & 5 & 22.8 & 46 \\
\hline 6 & 34.7 & 48 & 6 & 10.1 & 60 \\
\hline 7 & 21.9 & 68 & 7 & 21.8 & 64 \\
\hline 8 & 13.6 & 106 & 8 & 36.8 & 76 \\
\hline 9 & 6.0 & 104 & 9 & 20.1 & 54 \\
\hline 10 & 6.8 & 87 & 10 & 2.2 & 91 \\
\hline 11 & 10.8 & 112 & 11 & 42.3 & 145 \\
\hline 12 & 10.3 & 71 & 12 & 12.7 & 62 \\
\hline \multirow[t]{10}{*}{13} & 9.8 & 78 & 13 & 39.6 & 58 \\
\hline & & & 14 & 42.5 & 60 \\
\hline & & & 15 & 26.1 & 71 \\
\hline & & & 16 & 40.6 & 73 \\
\hline & & & 17 & 54.4 & 40 \\
\hline & & & 18 & 32.4 & 88 \\
\hline & & & 19 & 14.6 & 90 \\
\hline & & & 20 & 18.2 & 79 \\
\hline & & & 21 & 26.7 & 33 \\
\hline & & & 22 & 36.4 & 84 \\
\hline
\end{tabular}

The $m$ chromosomes are achiasmatic and negatively heteropycnotic until the end of meiosis; at diplotene they lie separated (Figure 1e, f), and, at late diakinesis, they associate forming a pseudobivalent. The nucleolus is detected from early meiotic prophase until late diplotene associated to one large bivalent (Figure 1c-f). This bivalent can show one or two terminal chiasmata and, generally, the secondary constriction of one of the homologues is more conspicuous than the other (Figure 1e, f). At metaphase I, the rod bivalents orientate axially (Figure 4a) and arrange with the $\mathrm{X}$ chromosome in a circle. At the centre of the hollow spindle, the $m$ pseudo-bivalent orientates axially. On the other hand, ring bivalents orientate equatorially (Figures $1 \mathrm{~h} \& 4 \mathrm{~b}$ ). When the bivalent without the secondary constriction has two chiasmata, one of them releases first and the bivalent finally reaches an axial orientation (Figure 4b, Type I). Nevertheless, when the NOR bivalent presents two chiasmata, no chiasma releases precociously (Figure $1 \mathrm{~h} \&$ Figure $4 \mathrm{~b}$, Type II). The secondary constrictions lead the migration to the poles at anaphase I; this bivalent lags but it finally segregates correctly to opposite poles (Figure 1i).

At anaphase $\mathrm{I}$, the autosomes and the $\mathrm{X}$ chromosome divide reductionally (Figure 1i, j). Consequently, metaphase II cells with and without the $\mathrm{X}$ chromosome are observed (Figure $1 \mathrm{k}, 1)$. At metaphase II, the autosomes and the $\mathrm{X}$ arrange in a circle with the $m$ chromosome at its centre. At anaphase II, the sex chromosome divides equationally and decondenses later (Figure 1m).

Chiasma frequency and distribution were analysed in 13 individuals in cells at diakinesis and metaphase I. The presence of one ring bivalent (of any of the two largest autosomal pairs) was frequently observed. Besides, a few cells with both of these pairs with two chiasmata and occasionally cells with three ring bivalents were seen. In $15.2 \%$ of the cells at diakinesis-metaphase I $(n=1049)$, the NOR bivalent presented two chiasmata with a highly variable frequency among individuals (Table 1). 


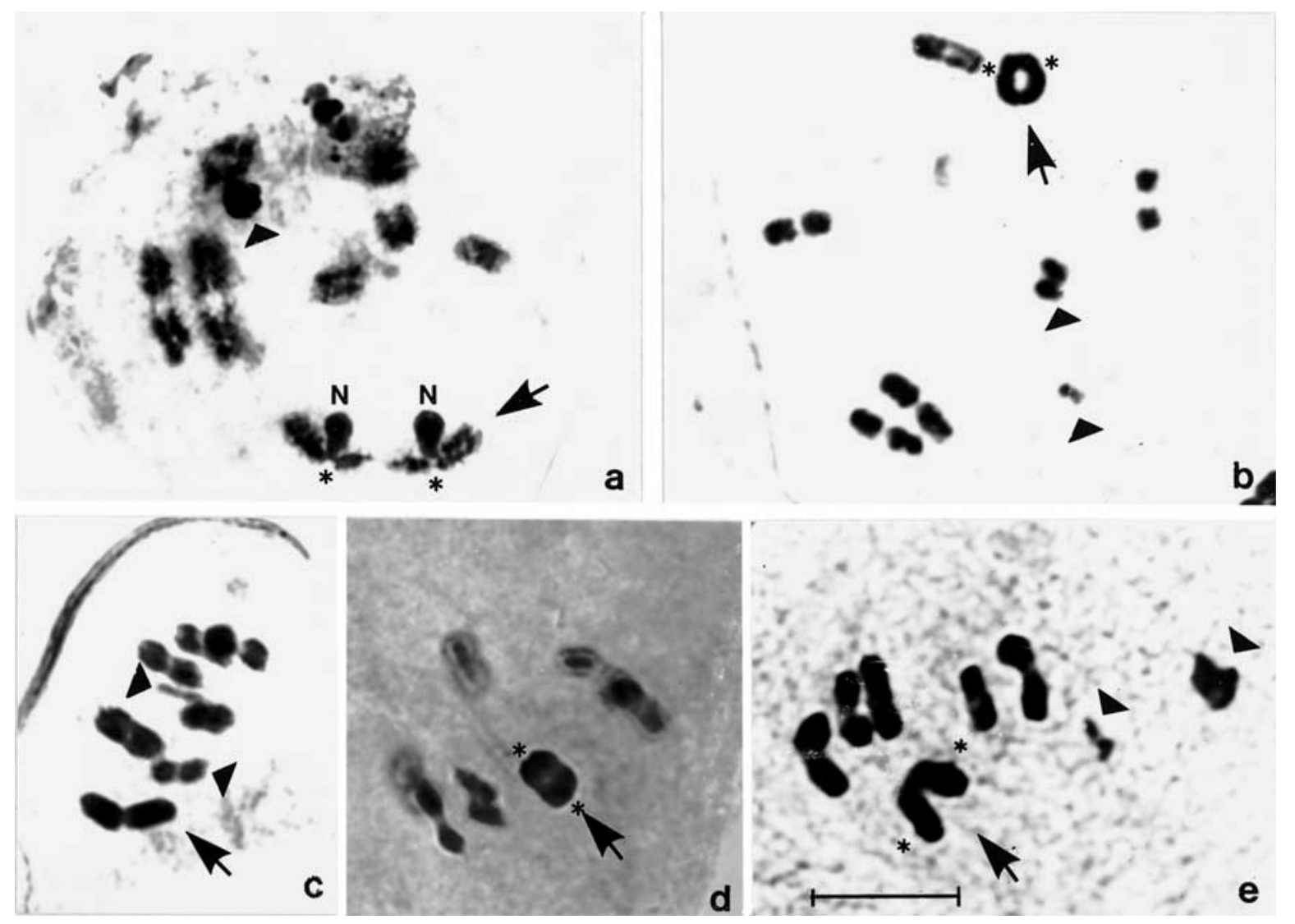

Figure 2. Male meiosis in Nezara viridula $(2 n=12+\mathrm{XY})$. (a, b) Diakinesis. (c, d) Metaphase I. The NOR bivalent can show one (a, c) or two (b, d) chiasmata. (e) Metaphase I with the NOR bivalent adopting a $V$ shape. Bar $=10 \mu \mathrm{m}$. Arrows point to the bivalent with the secondary constriction; arrowheads show the sex chromosomes. Asterisks indicate the secondary constrictions. $\mathrm{N}=$ nucleolus.

Nezara viridula possesses $2 n=14=12+\mathrm{XY}$ (male). A larger autosomal pair is recognized, while the other autosomes decrease gradually in size. The $\mathrm{X}$ chromosome is medium sized while the $\mathrm{Y}$ is the smallest of the complement. The largest autosomal pair presents a secondary constriction at a subterminal position.

Sex chromosomes are positively heteropycnotic from early prophase until diakinesis, when they turn isopycnotic (Figure 2a, b). The $\mathrm{X}$ and $\mathrm{Y}$ chromosomes generally lie close to one another. At the diffuse stage the autosomes decondense completely while the XY pair remains condensed. At diplotene and diakinesis, the secondary constriction of the NOR bivalent is clearly distinguished, and this bivalent can show either one or two chiasmata (Figure 2a, b). At metaphase I the autosomes arrange in a circle with the $\mathrm{X}$ and $\mathrm{Y}$ univalents lying a little apart (Figure 2e). Rod bivalents orientate axially while the NOR bivalent orientates axially when it has only one chiasma (Figure 2c) or equatorially when it has two chiasmata (Figure 2d). In a few cells, the NOR bivalent presents a $\mathrm{V}$ shape (Figure 2e). At anaphase I, autosomes divide reductionally and the sex chromosomes, equationally. At metaphase II, the autosomes dispose in a ring configuration with the XY pseudobivalent located at its centre.

Chiasma frequency and distribution were analysed in 22 individuals in cells at diakinesismetaphase I. Only the NOR bivalent presented two chiasmata and the ring bivalent was observed in $27.6 \%$ of the cells $(n=1589)$. Its frequency was also highly variable among individuals (Table 1 ). 


\section{Fluorescent in-situ hybridization}

Fluorescent signals were constantly observed on both sister chromatids of each homologue of the NOR bivalent in both Pachylis argentinus (Figure 3a-c) and Nezara viridula (Figure 3d-f).

When the NOR bivalent of $P$. argentinus presents only one chiasma, the fluorescent signals are observed in a medial position (Figure 3a). In this species, hybridization signals differ in size and intensity between homologues. On the other hand, in $N$. viridula, signals of nearly identical intensity are observed at a subterminal position in both homologues (Figure 3d). In both species, at metaphase I, the hybridization signals in the ring bivalents are detected facing the poles (Figure $3 b$ \& Figure 4b, Type II). Depending on the position adopted by the ring bivalent, four or only two signals are observed (Figure 3e \& Figure 4b, Type II). At anaphase I, the signals are observed on the chromosome regions that lead the movement of the homologues to the poles (Figure $3 \mathrm{f} \&$ Figure $4 \mathrm{~b}$, Type II). At metaphase II, the signals are observed in both chromatids of the chromosome (Figure 3c).

\section{Discussion}

Bivalents with two chiasmata have been recently reported in many species of Heteroptera but it is uncertain where the spindle fibres attach (Jacobs \& Liebenberg 2001, Jacobs \& Groeneveld 2002). In a cytogenetic study in Nezara viridula, Camacho et al. (1985) stated that ring bivalents should separate as half rings at anaphase I and kinetic activity probably involved other sites than chromosome ends.

In a previous report, we described the behaviour of the ring bivalents in Largus rufipennis (Largidae) and Belostoma oxyurum (Belostomatidae) (Mola \& Papeschi 1993). In these species, three
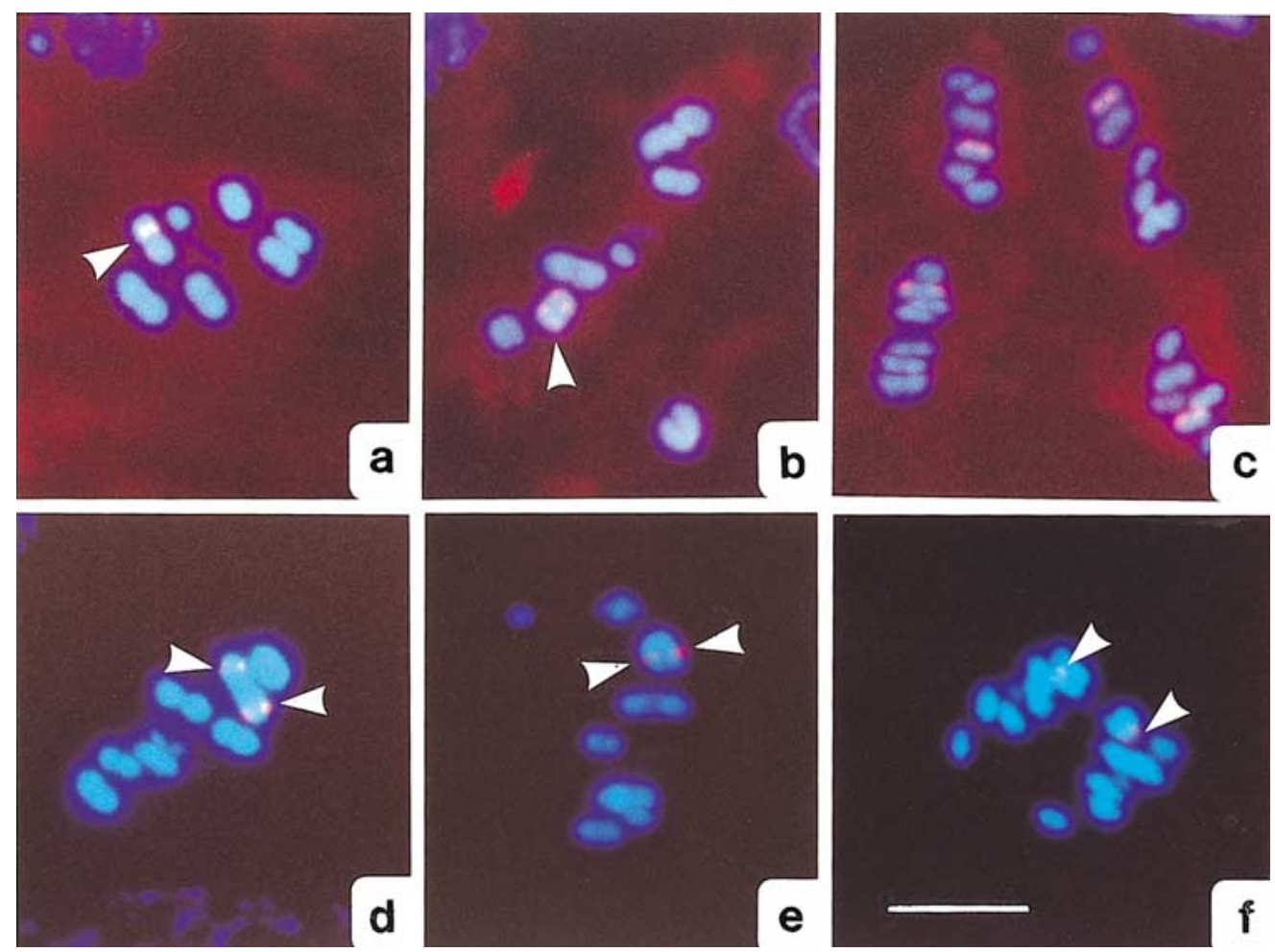

Figure 3. Hybridization signals of rDNA on Pachylis argentinus $(\mathbf{a}-\mathbf{c})$ and Nezara viridula $(\mathbf{d}-\mathbf{f})$ cells. The NOR bivalent can show only one chiasma (a, d) or two chiasmata (b, e). (c) Metaphase II. (f) Anaphase I; the hybridization signals are observed leading the migration to the poles. $\mathrm{Bar}=10 \mu \mathrm{m}$. 


\section{a-Meiotic behaviour of rod bivalents}
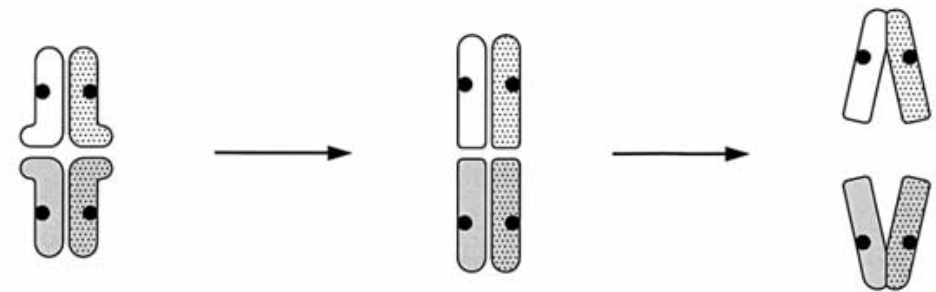

\section{b-Meiotic behaviour of ring bivalents}

Type I (without NOR regions)
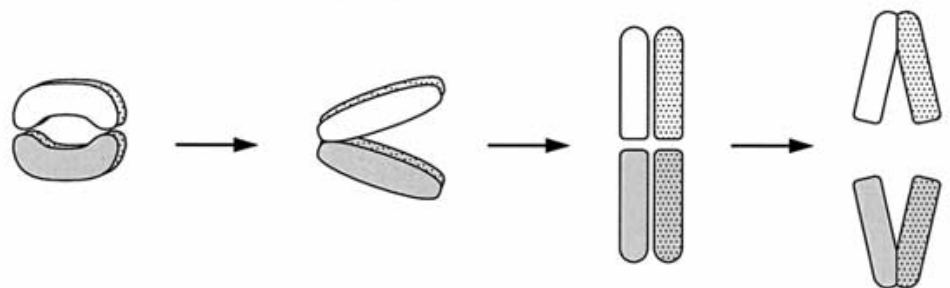

Type II (with NOR regions)
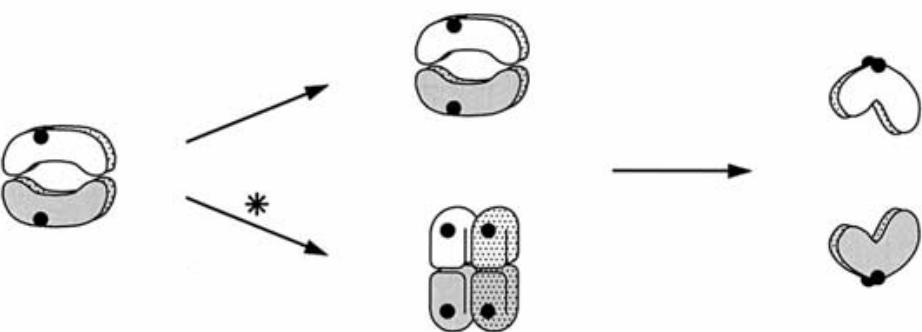

Figure 4. Diagrams illustrating the meiotic behaviour of bivalents with only one chiasma (a) or two chiasmata (b) from prometaphase I (left) to anaphase I (right). Dark dots represent the hybridization signals. (a) Rod bivalents orientate axially and one pair of telomeric regions leads the migration to the poles. (b) Ring bivalents orientate equatorially and can show two different modes of behaviour depending on the presence of a secondary constriction. Type I: one chiasma releases precociously, and the bivalent acquires a $\mathrm{V}$ shape. One pair of telomeric regions is free to attach to the spindle fibres and the bivalent finally reaches an axial orientation. Type II: when the bivalent presents a secondary constriction, the spindle fibres can attach to the nucleolus organizer regions and it is not essential that one of the chiasmata releases precociously. The diagrams at metaphase I illustrate different views of the NOR bivalent as shown in Figures $3 \mathrm{~b} \&$ e. At anaphase I, the NOR regions lead the chromosome migration to the poles. *The image is rotated around the Y-axis.

kinds of bivalents were observed at metaphase I: rod, ring and V-shaped bivalents (Figure 4b, Type I). Rod bivalents orientated axially and were firmly attached to the spindle fibres, while ring bivalents were equatorially orientated and seemed to be weakly attached. We proposed that, when one of the two chiasmata releases, one pair of telomeric regions becomes free to attach to the spindle, the bivalent adopts a $\mathrm{V}$ shape reaching finally a rod shape (Figure 4b, Type I). The large autosomal pair (devoid of a secondary constriction) of Pachylis argentinus follows this pattern. 
The in-situ hybridization with the rDNA probe corroborated that the secondary constrictions of $P$. argentinus and $N$. viridula are nucleolus organizer regions. In the former, FISH as well as the conventional staining revealed a NOR heteromorphism. This could be due to a different number of copies of rDNA genes in both homologues. Intra- and interindividual heteromorphisms, both in size and number of NORs, have been frequently reported in many aphid and coleopteran species (Bizzaro et al. 1999, Mandrioli et al. 1999, Vitturi et al. 1999, Sanchez-Gea et al. 2000).

The meiotic behaviour of the NOR bivalent when it has two chiasmata is different from that previously described. The ring bivalents orientate equatorially at the metaphase plate with the NORs facing opposite poles. We propose that it is not essential that one of the chiasmata releases first since the NOR bivalent is able to stabilize at the metaphase plate through the attachment of the spindle fibres at or near the NORs. At anaphase I, the NORs lead the chromosome migration to the poles (Figure $3 f \&$ Figure $4 b$, Type II). Although this behaviour is the most common for the NOR ring-shaped bivalents, in less than $1 \%$ of the cells of $N$. viridula, this bivalent presented a $\mathrm{V}$ shape, suggesting that one of the chiasmata had released. However, even in these cells, spindle fibres had probably attached first to the NORs (see Figure 2e).

Alternative sites of kinetic activity have been described in rye and maize monocentric chromosomes, in which neocentromeres are functional during meiosis but not in mitosis (Manzanero et al. 2000, Manzanero \& Puertas 2003). Manzanero \& Puertas (2003) concluded that the presence of the neocentromeres is not associated with a specific DNA centromeric sequence but with repetitive DNA that adopts a particular chromatin structure.

In the present work, we propose that, in $P$. argentinus and $N$. viridula, the chromatin packaging of meiotic chromosomes at or next to the nucleolus organizer regions is different from the bulk chromatin. This particular chromatin organization allows the attachment of microtubules to the secondary constrictions or repetitive DNA sequences adjacent to them.

Summarizing, in organisms with holokinetic chromosomes and a prereductional type of meiosis, as is the case in Heteroptera, not only telomeric regions but also secondary constrictions or sites next to them are capable of attaching to spindle fibres. It cannot be discarded that these alternative sites for microtubule attachment are also functional in rod bivalents, in which a competition for spindle attachment would take place. In these bivalents, the interaction between the NORs and the microtubules would be weaker and surpassed by the telomeres.

\section{Acknowledgements}

The present study was supported by the National Council of Scientific and Technological Research (CONICET). Grants from the Buenos Aires University (UBA) (X212) and the CONICET (PIP 4217) to Dr. L. Poggio and Dr. L. Mola, and from ANPCyT (PICT 01-08866) to Dr. A. Papeschi are gratefully acknowledged.

\section{References}

Bizzaro D, Barbolini E, Mandrioli M, Mazzoni E, Manicardi GC (1999) Cytogenetic characterization of the holocentric chromosomes in the aphids Myzus varians and Myzus cerasi. Caryologia 52: 81-85.

Bressa MJ, Papeschi AG, Larramendy ML (2001a) Meiotic studies in Lygaeus alboornatus Blanchard (Heteroptera, Lygaeidae: Lygaeinae). Caryologia 55: 15-19.

Bressa MJ, Papeschi AG, Mola LM, Larramendy ML (2001b) Autosomal univalents as a common meiotic feature in Jadera haematoloma and Jadera sanguinolenta (Heteroptera: Rhopalidae: Serinethinae). Eur J Entomol 98: 151-157.

Buck RC (1968) Mitosis and meiosis in Rhodnius prolixus: the fine structure of the spindle and diffuse kinetochore. $J$ Ultrastruct Res 18: 489-501.

Camacho JPM, Belda J, Cabrero J (1985) Meiotic behaviour of the holocentric chromosomes of Nezara viridula (Insecta, Heteroptera) analysed by C-banding and silver impregnation. Can J Genet Cytol 27: 490-497.

Comings DE, Okada TA (1972) Holocentric chromosomes in Oncopeltus: kinetochore plates are present in mitosis but absent in meiosis. Chromosoma 37: 177-192.

González-García JM, Antonio C, Suja JA, Rufas JS (1996) Meiosis in holocentric chromosomes: kinetic activity is randomly restricted to the chromatid ends of sex univalents in Graphosoma italicum (Heteroptera). Chromosome Res 4: $124-132$.

Grozeva S, Nokkala S (2001) Chromosome numbers, sex determining systems, and patterns of the C-heterochromatin distribution in 13 species of lace bugs (Heteroptera, Tingidae). Folia Biol (Krakòw) 49: 29-41. 
Jacobs DH, Groeneveld H (2002) Cytogenetics and karyotype evolution of the genus Silvacoris Jacobs (Heteroptera: Aradidae: Carventinae) with the description of a statistical method to compare karyotypes. Cytologia 67: $159-168$.

Jacobs DH, Liebenberg H (2001) Cytogenetics of Adamanotus uncotibialis Jacobs (Heteroptera: Aradidae). Caryologia 54: 83-96.

Mandrioli M, Manicardi GC, Bizzaro D, Bianchi U (1999) NOR heteromorphism within a parthenogenetic lineage of the aphid Megoura viciae. Chromosome Res 7: 157-162.

Manna GK (1984) Chromosomes in evolution in Heteroptera. In: Sharma AK, Sharma A, ed. Chromosomes in Evolution of Eukaryotic Groups. Boca Raton Florida USA: CRC Press, pp 189-225.

Manzanero S, Puertas MJ (2003) Rye terminal neocentromeres: characterisation of the underlying DNA and chromatin structure. Chromosoma 111: 408-415.

Manzanero S, Puertas MJ, Jiménez G, Vega JM (2000) Neocentric activity of rye 5RL chromosome in wheat. Chromosome Res 8: 543-554.

Marchant AD (1988) Apparent introgression of mitochondrial DNA across a narrow hybrid zone in the Caledia captiva species complex. Heredity 60: $39-46$.

Mola LM, Papeschi AG (1993) Meiotic studies in Largus rufipennis (Castelnau) (Largidae, Heteroptera): frequency and behaviour of ring bivalents, univalents and $B$ chromosomes. Heredity 71: 33-40.

Motzko D, Ruthmann A (1984) Spindle membranes in mitosis and meiosis of the heteropteran insect Dysdercus intermedius. A study of the interrelationship of spindle archi- tecture and the kinetic organization of chromosomes. Eur $J$ Cell Biol 33: 205-216.

Nokkala S, Grozeva S (2000) Achiasmatic male meiosis in Myrmedobia coleoptrata (Fn) (Heteroptera, Microphysidae). Caryologia 53: 5-8.

Papeschi AG, Mola LM (1990) Meiotic studies in Acanonicus hahni (Stål) (Coreidae, Heteroptera) I. Behaviour of univalents in desynaptic individuals. Genetica 80: 31-38.

Rebagliati P, Mola LM, Papeschi AG (2001) Karyotype and meiotic behaviour of the holokinetic chromosomes of six Argentine species of Pentatomidae (Heteroptera). Caryologia 54: 393-347.

Rebagliati P, Papeschi AG, Mola LM (2003) Meiosis and fluorescent banding in Edessa meditabunda and Edessa rufomarginata (Edessinae, Pentatomidae, Heteroptera). Eur $J$ Entomol 100: 11-18.

Sanchez-Gea JF, Serrano J, Galian J (2000) Variability in rDNA loci in Iberian species of the genus Zabrus (Coleoptera: Carabidae) detected by fluorescence in-situ hybridization. Genome 43: 22-28.

Suja JA, del Cerro AL, Page J, Rufas J, Santos JL (2000) Meiotic sister chromatid cohesion in holocentric sex chromosomes of three heteropteran species is maintained in the absence of axial elements. Chromosoma 109: 35-43.

Ueshima N (1979) Hemiptera II: Heteroptera. Gebrüder Borntraeger, Berlin-Stuttgart: John, B.

Vitturi R, Colomba MS, Barbieri R, Zunino M (1999) Ribosomal DNA location in the scarab beetle Thorectes intermedius (Costa) (Coleoptera: Geotrupidae) using banding and fluorescent in-situ hybridization. Chromosome Res 7: $255-260$. 